\title{
Investigating Volcanic Eruptions at Tafu: Chemical and Geographic Variation Within the NELSC
}

\author{
MALIA ZinN', Ken RUBiN', William W. CHADWICK JR², \\ SUSAN G. MERLE' \\ Department of Earth Sciences, University of Hawai'i at \\ Mānoa, Honolulu, HI 96822, USA (mzinn@hawaii.edu, \\ krubin@hawaii.edu) \\ ¿Oregon State University, CIMRS, Newport, OR 97365, USA \\ (william.w.chadwick@gmail.com, \\ susan.merle@noaa.gov)
}

Most volcanic eruptions on Earth are likely submarine; however, relatively little is known about deep-sea eruptions due to their difficulty in detection and observation [1]. The Northeast Lau Spreading Center (NELSC) and Northeast Lau Basin in general is one of the most volcanically active submarine provinces on Earth. We report here on three eruptions that occured at the NELSC submarine volcano Tafu in the past 15 years, and compare them to one at its next-ridge neighbor, Puipui [2]. The new Tafu eruption deposits were identified by bathymetric changes of up to $100 \mathrm{~m}$ between repeated multibeam sonar surveys conducted over the past two decades.

The Schmidt Ocean Institute Cruise FK171110 investigated recent volcanic eruptions in the NE Lau Basin with AUV and ship-based bathymetric mapping, and the remotely operated vehicle SuBastian in 2017, including these NELSC eruptions. It made two dives on the north and south flanks of Tafu. During these dives, photos and videos were taken, and rock and sediment samples were collected.

This project investigates the geochemistry and petrology of the samples collected, and how this relates to the locations in which they were emplaced. Synthesizing observations made from both electron microprobe analysis and photo/video evidence from the dives allows reconstruction of magma formation history and eruption conditions. Chemical, temporal, and spatial variations in the lavas will be presented and interpreted. The samples collected from both north and south Tafu are enriched basalts, but show significant geochemical and petrologic variation, due to parent magma and pre-eruptive magma storage variations, and differences in emplacement conditions.

[1] Rubin, Kenneth, et al., (2012) Oceanography, 25, no. 1, pp. 142-157., doi:10.5670/oceanog.2012.12.

[2] Baker, J.E. et al., (2011) Geochem. Geophys. Geosyst., 12, Article Number: Q0AF02 doi: 10.1029/2011GC003725 